\title{
Path Analysis on the Influence of Perceived Sport Competence by Other Motivational Variables 透過路線分析探索其他參與運動動機 對「勝任運動能力」的影響
}

\author{
Eric C.K. TSANG \\ Department of Creative Arts and Physical Education (PE Division) \\ The Hong Kong Institute of Education, HONG KONG
}

香港敉育學院體藝學系(體育學部)

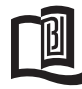

\begin{abstract}
The purpose of this study was to examine children's sport and physical education (PE) participation by focusing on perceived sports competence as suggested in Harter's competence motivation theory $(1978,1981)$. The study included other related factors of intrinsic/extrinsic motivational orientation, task/ego goal orientation and level of competitive trait anxiety to examine their relationship and predictive ability on perceived sport competence. A total of 2,202 participants from eleven schools of Secondary One, Two and Three, with a mean age of 13.55 years $(\mathrm{SD}=2.15)$ took part in this study. There was a proportional distribution of males $(n=1,056)$ and females $(n=1,130)$. Data was collected by using measuring instruments that included the Self-Perception Profile for Children (SPPC; Harter, 1985), Sport Motivation Scale (SMS; Pelletier et al., 1995), Task and Ego Orientation in Sport Questionnaire (TEOSQ; Duda \& Nicholls, 1989) and Sport Competition Anxiety Test (SCAT; Martens, Vealey \& Burton, 1990). Descriptive statistics were used to generalise the characteristics of the sample. Path analysis using EQS was performed to identify the structure of relationships between different attributes. The results revealed the relationships between perceived sport competence and other motivational attributes were mostly in accordance with Harter's competence motivation theory such that analyses demonstrated significant, modest, positive relationships with intrinsic motivation and extrinsic motivation, and negative relationships with anxiety and amotivation. The relationship with task goal orientation was significant but weak. Examination with path analysis showed that task goal orientation was related to perceived competence through the mediating effect of intrinsic and extrinsic motivation. By understanding how these factors affect children's decisions to continue or discontinue participation in PE and sport activities, and how these factors interact with each other, recommendations were made concerning the school PE curriculum and implementation of sport programmes in Hong Kong. Recommendations were also made for future studies.
\end{abstract}

\section{摘 要}

本研究是根據「勝任運動能力」及其他影響參與運動的因素包括「內在及外在動機」、「運動焦慮」及「目標定向」檢視 香港初中生參與運動的動機。2,202名中一至中三的學生參與這次問卷研究。數據分析總結出「勝任運動能力」與「內在動機」及 「外在動機」存在重要及正面關係, 與「運動焦慮」及「無動機」存在負面關係；通過結構公式分析顯示「任務目標」透過「內 在動機」及「外在動機」影響「勝任運動能力」。在了解這些影響青少年參與運動的因素後, 本研究作出一些提議及提出將來研 究的方向。 


\section{Introduction}

The study of motivated behaviour is paramount to sport educators in their quest for developing successful sport and physical education programmes. Taking different approaches, several conceptual perspectives have been proposed to better understand athletes' and leisureexercisers' motivation. In particular, Harter $(1978,1981)$ in her competence motivation theory, described and attempted to understand why people are motivated to continue or discontinue participation in various achievement areas, including sport and physical activity. Harter developed competence motivation theory by extending Robert White's (1959) model of effectance motivation. She developed the theory as a multidimensional framework to explain both the initiation of mastery attempts in particular achievement domains, and the development of achievement behaviours such as persistence, approach avoidance and striving for higher levels of competence or challenge. Competence motivation begins with individuals engaging in mastery attempts as an inherent desire to experience feelings of competence through demonstrating their abilities. If those mastery attempts are optimally challenging and success is attained, then increases in intrinsic pleasure, perceived competence, and internal perceptions of control are likely to occur. Furthermore, success from these mastery experiences often results in continued motivation to participate. On the other hand, repeated failures that involve increased anxiety, lower perceived competence, and an external locus of control result in sport withdrawal. In addition, the model depicts the influence of significant others and the use of rewards as having either positive or negative effects on the development of competence motivation.

Biddle (1997) identified competence motivation theory as a "domain-general self-perception" which was based on the assumption that individuals develop a global view of themselves and their abilities or adequacies in specific domains. Harter's (1978) competence motivation theory has been popular with sport psychology researchers and has been used frequently to examine youth sport participation.

There also exists a close relationship between one' $\mathrm{s}$ motivational orientation and perceived competence. Motivational orientation has several interacting components that comprise the individual's intention for participation (e.g., intrinsic/extrinsic motivation), selection of goals (e.g., task and ego), and perception of competitive situation (e.g., high/low anxiety).
Harter (1978) showed that intrinsic motivation is positively related to self-perceived competence. Other researchers (Ferrer-Caja \& Weiss, 2000; Klint \& Weiss, 1987; Markland, 1999; Weigand \& Broadhurst, 1998) have utilised different approaches to study perceived sport competence and intrinsic motivation. The results generally revealed that a positive relationship existed between perceived sport competence and intrinsic motivation, whereas a negative relationship occurred between perceived competence and amotivation. Some studies (Klint \& Weiss, 1987; Weigand \& Broadhurst, 1998) supported that intrinsic motivation is a good predictor of perceived competence. However, some studies (Ferrer-Caja \& Weiss, 2000; Markland, 1999) supported perceived competence as one of the predictors of intrinsic motivation alongside other mediating factors such as self-determination and goal orientations. Also, it has been found out that individuals can be high in both intrinsic and extrinsic motivations (Vlachopoulos, Karageorghis \& Terry, 2000); however, the relationship between extrinsic motivation and perceived competence has seldom been studied.

The relationship between perceived competence and goal orientations has been examined in a number of studies (Burton, 1989; Duda \& Chi, 1989; Duda et al., 1995; Duda \& Nicholls, 1992; Dunn, 2000; Hall, 1990; Seifriz et al., 1992). There has been considerable empirical support to indicate that a direct association exists between task goal orientation and perceived competence; and that participants in sport and exercise situations emphasising mastery climate are able to perceive feelings of competence and thus exert greater effort. However, the strength of the relationship between perceived competence and task-goal orientation has shown to be equivocal and sometimes has reflected a mediating and indirect role (William \& Gill, 1995).

Harter's competence motivation theory proposes that negative affect in the form of anxiety attenuates competence motivation when an individual perceives that one lacks the required competencies to achieve mastery, or does not possess adequate situational control. Other studies (Brustad \& Weiss, 1987; Ommundsen \& Pedersen, 1999; Ommundsen \& Vaglum, 1991; Passer, 1983) also revealed that high competitive trait anxiety was associated with low self-esteem and low perceived sport competence, and high perceived sport competence was typically associated with low competitive trait anxiety and enjoyment. Yet, most of the studies were conducted with athletes under competitive settings, rather than general physical activity settings. 
In sum, high perceived sport competence, high intrinsic motivation orientation and low amotivation, high task goal orientation, foster high participation in sport and physical activities. Also, low competitive trait anxiety is preferred in sport performance. Strong relationships have also been shown between perceived sport competence, and intrinsic motivation, task goal orientation and low competitive anxiety. However, the way in which these diverse motivational attributes interact with each other and, consequently, impact on participant motives, has to be examined.

This study examined the participation motive in sport activities from a competency perspective and particularly the relationships of perceived competence of participants with their adopted motivational orientations in Hong Kong junior secondary students were studied. With the implementation of the new secondary academic structure (3-3-4) in September 2006, it is essential to examine the underlining motivational forces of junior secondary students that affect their participation in sport and physical activities. Such findings can generate recommendations for the reform of the junior secondary physical education curriculum in order to attract more students to choose PE as one of the elective subjects in their senior secondary.

To explore the relationships between different motivational variables and test whether these variables were able to predict perceived sport competence, path analysis using structural equation modelling (SEM) was conducted. A hypothesised structural model was built and tested whether it was meaningful. In this study, a hypothesised model (Mh) was devised based on the assumptions that the motivational variables of task/ego goal orientation, intrinsic/extrinsic motivation, amotivation and competitive trait anxiety were closely related with each other and, at the same time, had direct influence on perceived sport competence (Figure 1). The model was tested to evaluate whether the hypotheses were valid with the aid of various fit indexes.

\section{Figure 1. Hypothesized Multiple Regression Path Model (Mh) of Relationships among the Variables.}

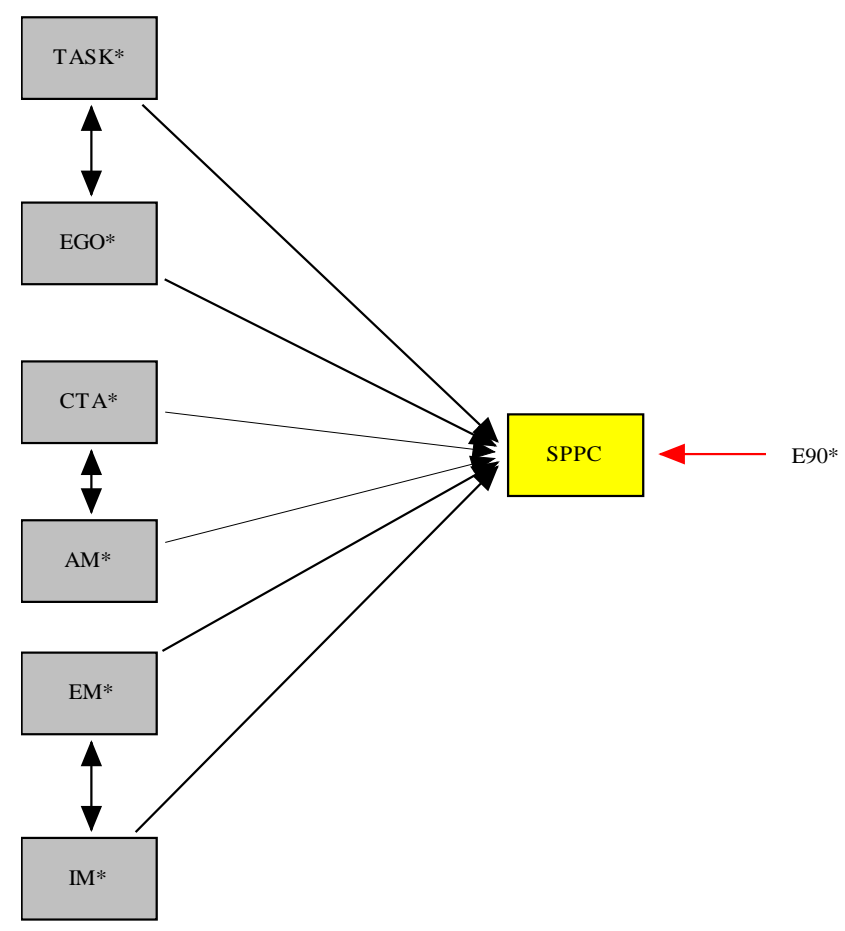

Note. TASK = task goal orientation; $E G O=$ ego goal orientation; $C T A=$ competitive trait anxiety; $A M=$ amotivation; $E M=$ extrinsic motivation; $I M=$ intrinsic motivation; $S P P C=$ perceived sport competence

Continuous lines indicate positive relationship; discontinuous lines indicate negative relationship

\section{Method}

\section{Participants}

Junior secondary (S.1 to S.3) school children were studied in this investigation. A total of 2,202 participants from eleven schools took part in this study. Schools were selected by proportional stratification based on the region which covered all seven Districts in Hong Kong according to the division made by the Hong Kong Schools Sports Federation (2000). In each school, a total of six classes - two from Secondary 1, 2 and 3 were tested, with approximately 38 students in each class. In some schools, class size was smaller with about 30 in each class. Consequently, the proportion of students in each grade was evenly distributed $(\mathrm{S} .1=735 ; \mathrm{S} .2=737$; and S. $3=$ 730). Participants had a mean age of 13.55 ( $\mathrm{SD}=2.15$ years) ranging from 12 to 17 years, inclusive. There was also a fairly equal distribution of males and females. 


\section{Instruments}

Self-Perception Profile for Children (SPPC; Harter, 1985)

Harter developed the Self-Perception Profile for Children (SPPC) in 1985 to tap children's domain-specific judgments of their competence and global perception of self-worth as a person. The instrument provided separate measures of an individual's perceived competence in different areas that could yield a more differentiated and contextual view of self-concept. The seven domains were cognitive competence, social competence, athletic competence, physical appearance, behaviour conduct and global self-worth. The instrument is appropriate for children in the third through sixth grades (8 to 12 years). The internal consistency reliabilities (Cronbach' $\mathrm{s}$ alpha) for each subscale range between .71 to .86 have been reported by Harter (Harter, 1985), and have been confirmed by other studies (Granleese \& Joseph, 1993; Van Dongen-Melman, Koot, \& Verhulst, 1993; Worth Gavin \& Herry, 1996). Each subscale has six items presented in a structured alternative format. Two statements reflecting opposing views of a child were presented to children, and they went through a two-step process in responding to the items. In the current study, only the physical appearance and athletic competence subscales were used since the study was concentrating on physical activity-related areas.

\section{Sport Motivation Scale (SMS; Pelletier et al., 1995)}

The Sport Motivation Scale (SMS) was validated by Pelletier and his colleagues (Pelletier et al., 1995) as an English version of the original 'Echelle de Motivation dans le Sport' (EMS; Briere et al., 1995). The SMS is based on the conceptualisation of different motivational constructs by Deci, Ryan and colleagues (Ryan, Connell \& Grolnick, 1992; Ryan \& Deci, 2000) and also Vallerand and colleagues (Vallerand et al., 1992, 1993). It is multidimensional in nature, and is composed of seven subscales that consist of three types of extrinsic motivation (extemal, introjected, and identified regulation), three types of intrinsic motivation (intrinsic motivation to know, to experience stimulation, and to accomplish) and the concept of amotivation. In a study conducted by Pelletier et al. (1995), a mean Cronbach alpha of .82 was reported and a mean test-retest reliability coefficient of .69 was found across a one-month interval.
Task and Ego Orientation in Sport Questionnaire (TEOSQ; Duda \& Nicholls, 1989)

Nicholls collaborated with Duda in developing the sport-specific Task and Ego Orientation in Sport Questionnaire (TEOSQ) (Duda \& Nicholls, 1989). Participants are asked to think of a successful sport experience and respond to 13 items reflecting task- and ego-referenced criteria. Responses are indicated on a 5-point Likert Scale ranging from strongly disagree (1) to strongly agree (5). From a summarised data of 56 studies that included a range of ages from 10-12 years with school children, as well as adolescents, adults and senior citizens, Duda and Whitehead (1998) reported mean internal reliability value of .79 and .81 , respectively, for the task and ego subscales of TEOSQ.

\section{Sport Competition Anxiety Test (SCAT; Martens et al., 1990)}

Competitive anxiety was measured with the Sport Competition Anxiety Test (SCAT) that was developed in response to the need for a sport-specific measure of trait anxiety (Martens, 1977; Martens et al., 1990). The SCAT is used to assess individual differences in competitive trait anxiety, or the tendency to perceive competitive situations as threatening and respond to these situations with elevated state anxiety. The SCAT contains 15 items, and participants are asked to indicate how they generally feel when they compete in sports and games and respond to each item using a 3-point ordinal scale (hardly ever, sometimes, or often). SCAT has good internal reliability (KR-20 coefficient ranged from .95 to .97) and also demonstrated an acceptable test-retest reliability (Pearson $r=.77$ ).

\section{Demographic variables}

Demographic variables include participant's present educational level in school (i.e., Secondary 1, Secondary 2 or Secondary 3), gender, age, district of residence, and level of participation in sport activities (i.e., seldom, recreational, and training).

\section{Procedures}

Translation of the questionnaires into Chinese followed the parallel back-translation procedure. The original questionnaires were translated into Chinese by the investigator, and then the Chinese version was translated back into English by another teacher educator who was fluent in both English and Chinese languages. The 
Chinese instruments were refined until both translators were satisfied with them. Subsequently, the final versions of the questionnaires were word-processed in Chinese and bundled together before their distribution for completion by the students. Informed Consent letters were prepared and sent to the school Principal. After obtaining permission, the questionnaires were distributed and completed at the beginning of their physical education classes. The majority of the students completed the four questionnaires in approximately 15 minutes.

\section{Data Analysis}

The ratings of the questionnaires were entered into an Excel file rating by rating, which later was imported into a Statistical Package for Social Sciences (Version 12.0) data file for subsequent analyses. The questionnaire items were reduced to seven subscales: task goal orientation (TASK), ego goal orientation (EGO), competitive trait anxiety (CTA), amotivation (AM), extrinsic motivation (EM), intrinsic motivation (IM) and perceived sport competence (SPPC). To explore the relationships between the different variables of goal orientation, motivational orientations and anxiety, and test whether these variables were able to influence perceived sport competence, path analysis using structural equation modelling (SEM) was conducted using the EQS for Windows 6.1 statistical package (Bentler, 1995). Statistical recommendations from the Lagrange Multiplier (LM) Test and the Wald Test were used for the amendments of the hypothesised model. A cutoff value close to or greater than .95 for comparative fit index (CFI) in combination with a cutoff value close to or smaller than .08 for standardized root mean squared residual (SRMR) were used to evaluate model fit as recommended by $\mathrm{Hu}$ and Bentler (1999). To fully evaluate the model, the total sample was randomly split into two groups by using SPSS for Windows V.12. The first sample was used to test the hypothetical model (Mh). By considering the fitness indexes and recommendations from LM test and Wald test, the model was appropriately revised. The revised model was re-tested using the same sample. In obtaining satisfactory fit of index, the second sample was used to verify the modified model. Finally, both samples were merged and entered into the modified model. Outputs from the analysis were interpreted with reference to the literature.

\section{Results}

Findings from path analysis are provided below. Significant results are all represented at the level of $\mathrm{p}<$ .05 , unless otherwise specified.

Path analysis by using structural equation modelling was used to test the hypothesised model (Mh) (Figure 1). In order to verify the fitness of the model, the total sample was randomly split into two groups via the use of SPSS for Windows V. 12.0. Sample $1(\mathrm{n}=1,101)$ was used to test the hypothesised structural model. Goodness of fit was assessed by examining the Comparative Fit Index (CFI) and standardized root mean squared residual (SRMR). The fit indices that emerged from the analyses indicated a poor model fit with the data $(\mathrm{CFI}=.76$, SRMR = .13) which were beyond the cutoff criteria for fit index (Hu \& Bentler, 1999). The Lagrange Multiplier (LM) test suggested that paths should be added between task goal orientation and intrinsic motivation, task goal orientation and extrinsic motivation, ego goal orientation and competitive trait anxiety, amotivation and extrinsic motivation. Another modified model (Mp) was tested again with the first sample and yielded a good fit index (CFI $=.95 ;$ SRMR $=.08)$ which met the recommended cutoff criteria for fit index (Hu \& Bentler, 1999) (see Figure 2).

\section{Figure 2. Multiple Regression Hypothesised Path Model (Mp) tested with Sample 1 (n = 1,101) $($ CFI = .95; SRMR=.08).}

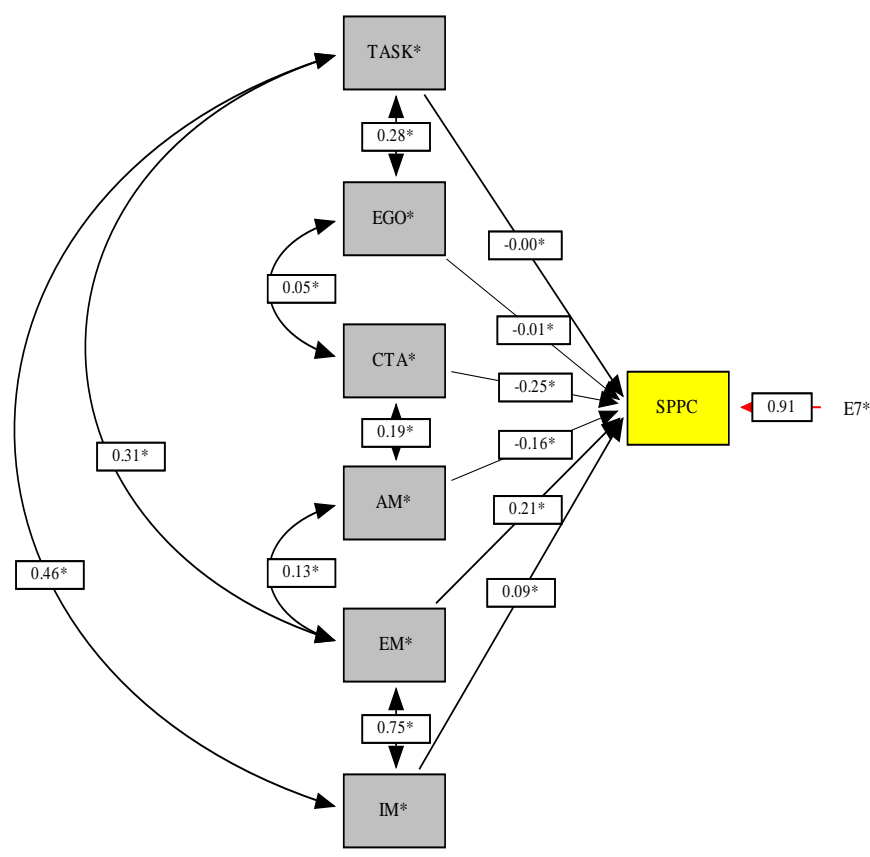

Note. Continuous lines indicate positive relationship; discontinuous lines indicate negative relationship 
However, it was noted that the path coefficients from task goal orientation and ego goal orientation to perceived sport competence were low. Further examination was conducted by using the Wald test, and findings revealed that the paths connecting the task goal and ego goal orientations with perceived sport competence should be dropped which would result in a more parsimonious model. In consideration of the weak relationship between task goal orientation and perceived sport competence, yet modest relationships between task goal orientation and intrinsic and extrinsic motivations, it is logical to hypothesise that task goal orientation was able to influence perceived sport competence only through the moderators of intrinsic motivation and extrinsic motivation. Also, the significant relationship between intrinsic motivation and extrinsic motivation suggested that the intervening variable (task goal orientation) did not fully explain the covariation between the two variances of intrinsic motivation and extrinsic motivation. Considering the nature of intrinsic motivation and extrinsic motivation, there should be some common factors (such as enjoyment, satisfaction) that might explain this co-variation, so the estimation of the correlation between the residual variance of intrinsic motivation and residual variance of extrinsic motivation was maintained in the modified model (Figure 3). The modified model was tested again with the Sample 1 and yielded very good fit indices $(\mathrm{CFI}=.97$; SRMR $=.04)$.

Figure 3. Multiple Regression Hypothesised Path Model.
To verify the validity of the model, Sample $2(n=1,101)$ was tested with the modified model as recommended for structural equation modelling analyses (Tabachnick \& Fidell, 1996). Again, the fit indices that emerged indicated a very good fit $(\mathrm{CFI}=.97 ;$ SRMR $=.04)$. Multi-group analysis testing invariance of path coefficients and residual variances across the two samples supported equality of all estimated parameters.

Following the results of the multi-group analysis, the two samples were combined $(\mathrm{N}=2,202)$ and the revised model was tested. As expected, the fit indexes were very $\operatorname{good}(\mathrm{CFI}=.97 ;$ SRMR $=.04)$ (Figure 4). As hypothesised, the paths connecting perceived sport competence with competitive trait anxiety (path coefficient $=-.24$ ) and amotivation (path coefficient $=-.15$ ) were negative and significant. The relationships between perceived sport competence and extrinsic motivation (path coefficient $=.18$ ) and intrinsic motivation (path coefficient $=.11$ ) were both positive and significant. Task goal orientation did not demonstrate a strong relationship directly with perceived sport competence, but strong relationships were found between task goal orientation with intrinsic motivation (path coefficient $=.53$ ) and extrinsic motivation (path coefficient $=.38$ ). Through the moderators of intrinsic motivation and extrinsic motivation, task goal orientation affected perceived sport competence. Overall, $16.4 \%$ of the variance in perceived sport competence was explained by competitive trait anxiety, amotivation, extrinsic motivation, intrinsic motivation and task goal orientation.

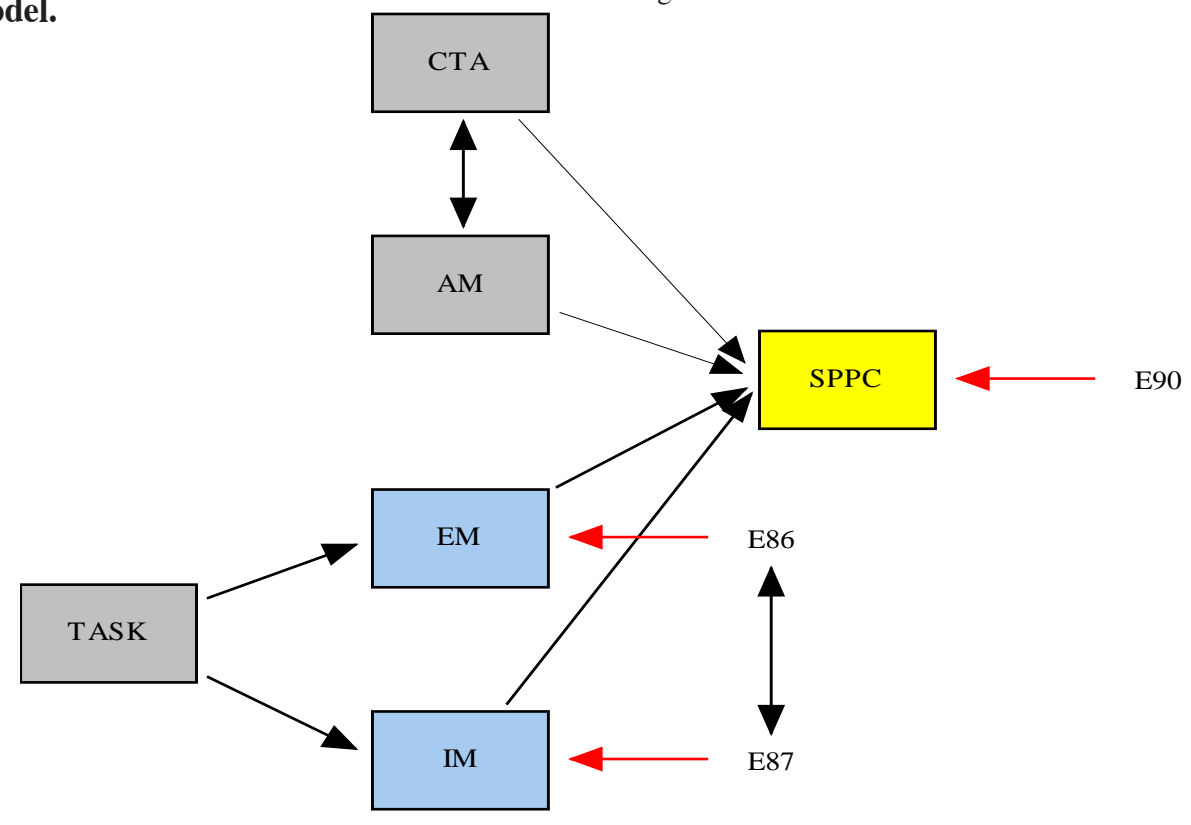

Note. Continuous lines indicate positive relationship; discontinuous lines indicate negative relationship 
Figure 4. Multiple Regression Path Model for the Total Sample $(\mathrm{N}=2,202)(\mathrm{CFI}=.97$; SRMR = .04).

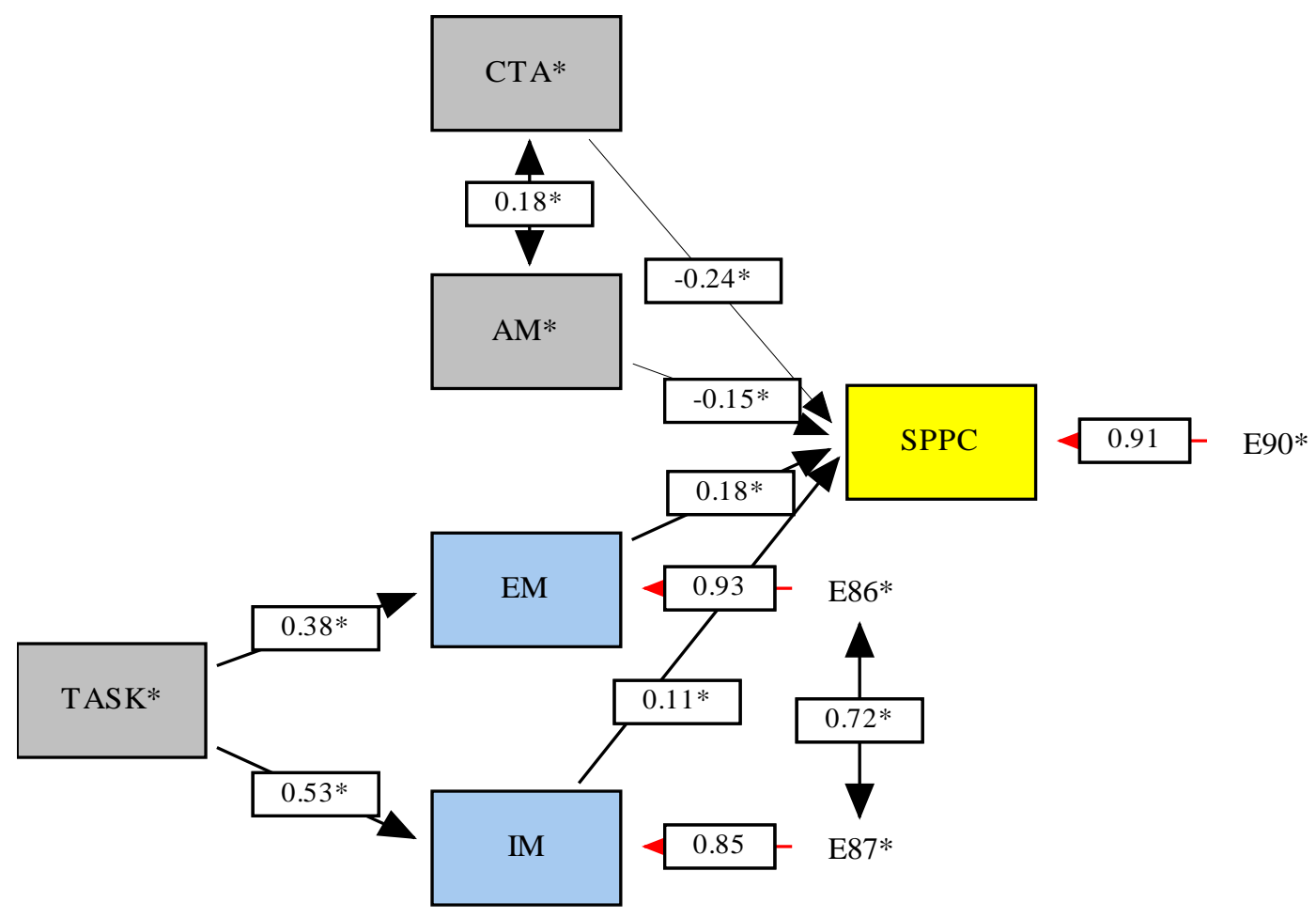

Note. Continuous lines indicate positive relationship; discontinuous lines indicate negative relationship All paths were significant $(p<.01)$

\section{Discussion}

A proposed model was built and tested with the data collected from the current study to investigate the relationships among different factors of intrinsic and extrinsic motivation, amotivation, goal orientation and anxiety, and examined their predictive ability with regard to perceived sport competence. The proposed model showed that over $16 \%$ of the variance in perceived competence was accounted for by the factors of types of motivations, goal orientations and anxiety. This was a modest prediction given the likelihood that much less variance in perceived sport competence would be predicted from such a model. Nevertheless, given the importance of sport participation for young people in this current society where health is a main concern, this $16 \%$ is certainly meaningful if teachers are able to increase their students' sport involvement by equivalent amounts. With regard to the source of perceived sport competence, intrinsic motivation and extrinsic motivation played a positive role that might enhance the feeling of competency; while anxiety and amotivation played a negative role that might deter perceived sport competence.
One major finding of the path analysis confirmed the influence of competitive trait anxiety on perceived sport competence. Among the different variables, competitive trait anxiety served as the strongest predictor which was able to explain $6 \%$ of the variance of perceived sport competence. This finding clarified the role of competitive trait anxiety in perceived competence that was not clear in some of the previous studies (Brustad, 1988; Brustad \& Weiss, 1987; Passer, 1983). Furthermore, the finding was in accordance with the Harter's competence motivation theory which states that affective experiences in sport, such as anxiety, are directly related to underlying perceptions of self-worth, personal ability, and internal control over outcomes, and that these are the fundamentals of an individual's perception of competence.

In order to maintain or enhance an individual's feeling of competence, the environment should be controlled such that perceptions of threats and/ or thoughts that signify some kind of threat must be minimised. In school physical education classes, this kind of threatening feeling most likely arose when the students felt that they were being assessed by their 
by their peers. This finding alerts educationalists and school administrators that over-assessment or assessmentcentred curriculum can have an adverse effect on students' intentions for sport participation.

Results also revealed that anxiety and amotivation were inter related, or that there existed a reciprocal effect between the two variables. Anxiety could have decreased children's desires to participate and, essentially lead to their amotivation. Also, students that had a lack of intent to engage in sport activities would have been more likely to generate anxious feelings when they were required to take part in physical activities. Both amotivation and competitive trait anxiety tended to lower an individual's perceived competence. This finding once again emphasised the importance of providing fun and opportunities of success for students by selecting appropriate and meaningful activities during physical activity sessions.

Both extrinsic motivation and intrinsic motivation were significant predictors of perceived sport competence. This result is in accordance with previous studies (FerrerCaja \& Weiss, 2000; Klint \& Weiss, 1987; Markland, 1999; Weigand \& Broadhurst, 1998; Williams \& Gill, 1995). The two types of motivation also served as strong mediating variables in the task goal orientation and perceived sport competence relationship.

Task goal orientation did not demonstrate a direct and positive link with perceived competence as found in previous studies (Duda \& Nicholls, 1992; Seifriz et al., 1992), but findings were in agreement with other studies (Duda et al., 1992; Duda et al., 1995) whereby strong relationships were found with intrinsic motivation and extrinsic motivation. This implied that adopting a task goal orientation would not directly enhance perceived competence. However, through adopting a task goal orientation, the level of intrinsic and extrinsic motivation could effectively be heightened. Through the mediators of intrinsic and extrinsic motivations, perceived sport competence could be enhanced. In view of this, P.E. teachers and sport administrators should work towards installing self-referenced criteria for defining competence among students and young athletes when designing the P.E. curriculum or selection of sport activities. Also, it is important to empower young people to consider that ability is an acquirable skill as this can result in enhanced perceptions of self-efficacy as noted by Jourden et al. (1991).
In the current study, ego goal orientation did not show a significant facilitating effect on perceived competence which was congruent with previous research (Duda et al., 1995; Seifriz et al., 1992). This finding implied that when participating in sport activities, individuals who always intend to outperform others and appraise their ability with reference to others' performances are not likely to foster their perceived competence. Consequently, teachers and sport administrators should avoid emphasising comparison with others during P.E. lessons and sport activities.

\section{Conclusion}

In light of the findings from this study, school PE programs in Hong Kong should aim at promoting intrinsic and extrinsic motivations in order to foster children's feeling of competence; minimising anxious feelings during participation; preventing amotivation in sport and physical activity participation; and emphasising task goals which can heighten both intrinsic and extrinsic motivation and, subsequently, contribute to children's perceptions of competence.

The design of the present study was cross-sectional and investigation-based. Hence, the reliabilities of the variables are associated with the design of the model as inferred from structural equation analysis (Ullman, 2001). An extension of the present study may include longitudinal designs in which multiple data points are assessed across different participatory phases of sport involvement. Another highlight of Harter's competence motivation theory $(1978,1981)$ was the role of significant others in shaping children's self-perceptions. Significant adult influence in the form of parents and teachers, and peer group influence that includes support and socialisation can have a detrimental influence on an individual's perception of competence, according to the theory. In consideration of a unique Eastern culture, where the family influence has primary importance, it is worthwhile to include these social factors into the model in order to investigate how they in influence children's motive towards participation in sport and physical activities in Hong Kong. Some of the findings in this research are not in line with the main stream studies in the West. For example, participants in this study had a high perception in both task and ego goal orientations. In fact, most of the published research in sport psychology has been conducted with Western participants. There have been critiques in the literature 
that cite the necessity for ethnic and cultural factors to be incorporated in the research (Duda \& Allison, 1990; Markus \& Kitayama, 1991; Si, 2000). More crosscultural studies are required to verify the generalisability of existing theories and to explore variations between different cultures as a means to develop relevant theory and practice that is adapted for the diversity of cultures. According to Weiss and Ferrer-Caja (2002), there are many factors, such as the perception of the environment, the feeling of affiliation, that influence the formation of perceptions of ability and likelihood to maintain motivation in sports. Additional research is thus warranted to explore and generate information on other factors that influence children's motivation.

In conclusion, this study attempted to extend our knowledge base of motivation of junior secondary school students in Hong Kong towards participation in sport and physical activities by examining the structure of relationships between perceived sport competence and other motivational constructs of intrinsic/extrinsic motivation, task/ego goal orientation and competitive trait anxiety. By understanding these variables that influence school children in sport participation and how they interact is important for helping young people to develop a healthy habit of exercise adherence. While previous sport motivational researches have been studied mostly on western culture, the results from this study can supplement to the existing knowledge by incorporating information obtained in Hong Kong. Thus, it is anticipated that research of this kind will prosper when sport administrators realize that the behaviour of the children have to be considered for the development of effective sport and physical activity programmes.

\section{References}

Bentler, P.M. (1995). EQS structural equation program manual. Encino, C.A.: Multivariate Software, Inc.

Black, S.J., \& Weiss, M.R. (1992). The relationship among perceived coaching behaviours, perceptions of ability, and motivation in competitive age-group swimmers. Journal of Sport \& Exercise Psychology, 14, 309-325.

Blais, M.R., Sabourin, S., Boucher, C., \& Vallerand, R.J. (1990). Toward a motivational model of couple happiness. Journal of Personality and Social Psychology, 59, 1021-1031.
Biddle, S.J.H. (1997). Cognitive theories of motivation and the physical self. In K.R. Fox (Ed.), The physical self: From motivation to well-being (pp. 59-82). Champaign, IL: Human Kinetics.

Briere, N.M., Vallerand, R.J., Blais, M.R., \& Pelletier, L.G. (1995). Development et validation d'une mesure de motivation intrinseque, extrinseque et d'amotivation en contexte sportif: l'Echelle de Motivation dans les Sports (EMS). [Development and validation of the French form of the Sport Motivation Scale]. International Journal of Sport Psychology, 26, 465-489.

Brustad, R.J. (1988). Affective outcomes in competitive youth sport: The influence of intrapersonal and socialization factors. Journal of Sport and Exercise Psychology, 10, 307-321.

Brustad, R.J., \& Weiss, M.R. (1987). Competence perceptions and sources of worry in high, medium, and low competitive trait-anxious young athletes. Journal of Sport Psychology, 9, 97-105.

Burton, D. (1989). Winning isn't everything: Examining the impact of performance goals on collegiate swimmers' cognitions and performance. The Sport Psychologist, 3, 105-132.

Duda, J.L. (1992). Sport and exercise motivation: A goal perspective analysis. In G.C. Roberts (Ed.), Motivation in sport and exercise (pp. 57-91). Champaign, IL: Human Kinetics.

Duda, J.L., \& Allison, M.T. (1990). Cross-cultural analysis in exercise and sport psychology: A void in the field. Journal of Sport \& Exercise Psychology, 12, 114-131.

Duda, J.L., \& Chi, L. (1989, September). The effect of task- and ego-involving conditions on perceived competence and causal attributions in basketball. Paper presented at the meeting of the Association for the Advancement of Applied Sport Psychology, University of Washington, Seattle.

Duda, J.L., Chi, L., Newton, M.L., Walling, M.D., \& Catley, D. (1995). Task and ego orientation and intrinsic motivation in sport. International Journal of Sport Psychology, 26, 40-63. 
Duda, J.L., Fox, K.R., Biddle, S.J.H., \& Armstrong, N. (1992). Children's achievement goals and beliefs about success in sport. British Journal of Educational Psychology, 62, 313-323.

Duda, J.L., \& Nicholls, J.G. (1989). The task and ego orientation in sport questionnaire: Psychometric properties. Unpublished manuscript.

Duda, J.L., \& Nicholls, J.G. (1992). Dimensions of achievement motivation in schoolwork and sport. Journal of Educational Psychology, 84, 1-10.

Duda, J.L., \& Whitehead, J. (1998). Measurement of goal perspectives in the physical domain. In J.L. Duda (Ed.), Advances in sport and exercise psychology measurement (pp. 21-48). Morgantown, WV: Fitness Information Technology.

Dunn, J.C. (2000). Goal Orientations, perceptions of the motivational climate, and perceived competence of children with movement difficulties. Adapted Physical Activity Quarterly, 17, 1-19.

Ferrer-Caja, E., \& Weiss, M.R. (2000). Predictors of intrinsic motivation among adolescent students in physical education. Research Quarterly for Exercise and Sport, 71 (3), 267-279.

Granleese, J., \& Joseph, S. (1993). Factor analysis of the Self-Perception Profile for Children. Personality and Individual Differences, 15, 343-345.

Harter, S. (1978). Effectance motivation reconsidered. Human development, 21, 34-64.

Harter, S. (1981). A model of intrinsic mastery motivation in children: Individual differences and developmental change. In W. Collins (Ed.), Minnesota Symposium on Child Psychology. Hillsdale, NJ: Erlbaum.

Harter, S. (1985). Manual for the self-perception profile for children. Denver: University of Denver.

Hong Kong Schools Sports Federation. (2000). Member schools handbook.

Hu, L.T., \& Bentler, P.M. (1999). Cutoff criteria for fit indexes in covariance structure analysis: Conventional criteria versus new alternatives. Structural Equation Modeling, 6(1), 1-55.
Jourden, F.J., Bandura, A., \& Banfield, J. (1991). The impact of conceptions of ability on self-regulatory factors and motor skill acquisition. Journal of Sport \& Exercise Psychology, 8, 213-226.

Klint, K.A., \& Weiss, M.R. (1987). Perceived competence and motives for participating in youth sports: A test of Harter's competence motivation theory. Journal of Sport Psychology, 9, 55-65.

Markland, D. (1999). Self-determination moderates the effects of perceived competence on intrinsic motivation in an exercise setting. Journal of Sport and Exercise Psychology, 21, 351-361.

Markus, H.R., \& Kitayama, S. (1991). Culture and the self: Implications for cognition, emotion, and motivation. Psychological Review, 98, 224-253.

Martens, R. (1977). Sport competition anxiety test. Champaign, IL: Human Kinetics.

Martens, R., Vealey, R.S., \& Burton, D. (1990). Competitive anxiety in sport. Champaign, IL: Human Kinetics.

Nunnally, J.C., \& Bernstein, I.H. (1994). Psychometric Theory. New York: McGraw-Hill.

Ommundsen, Y., \& Pedersen, B.H. (1999). The role of achievement goal orientations and perceived ability upon somatic and cognitive indices of sport competition trait anxiety. Scandinavian Journal of Medicine and Science in Sports, 9, 333-343.

Ommundsen, Y., \& Vaglum, P. (1991). Soccer competition anxiety and enjoyment in young boy players. The influence of perceived competence and significant others' emotional involvement. International Journal of Sport Psychology, 22, 35-49.

Passer, M.W. (1983). Fear of failure, fear of evaluation, perceived competence, and self-esteem in competitive trait anxious children. Journal of Sport Psychology, 5, 172-188.

Pelletier, L.G., Tuson, K.M., Fortier, M.S., Vallerand, R.J., \& Briere, N.M. (1995). Toward a new measure of intrinsic motivation, extrinsic motivation, and amotivation in sports: the sport motivation scale (SMS). Journal of Sport and Exercise Psychology, 17, 35-53. 
Ryan, R.M., Connell, J.P., \& Grolnick, E.S. (1992). When achievement is not intrinsically motivated: A theory and assessment of self-regulation in school. In A.K. Boggiano \& T.S. Pittman (Eds.), Achievement and motivation: A social-developmental perspective (pp. 167-188). Cambridge, UK: Cambridge University Press.

Ryan, R.M., \& Deci, E.L. (2000). Self-determination theory and the facilitation of intrinsic motivation, social development, and well being. American Psychologist, 55, 68-78.

Seifriz, J.L., Duda, J.L., \& Chi, L. (1992). The relationship of perceived motivational climate to intrinsic motivation and beliefs about success in basketball. Journal of Sport \& Exercise Psychology, 14, 375-391.

Si, G. (2000). The indigenous study and the cross-cultural study in sport psychology. Sport Science, 20, 74-78.

Tabachnick, B.G.. \& Fidell, L.S. (2001). Using Multivariate Statistics. New York: Harper Collins.

Ullman, J.B. (2001). Structural Equation Modeling. In Tabachnick, B.G., \& Fidell, L.S. (Ed.), Using Multivariate Statistics (pp.653-771). New York: Harper Collins.

Vallerand, R.J., Pelletier, L.G., Blais, M.R., Briere, N.M., Senecal, C., \& Vallieres, E.F. (1992). The Academic Motivation Scale: A measure of intrinsic, extrinsic, and amotivation in education. Educational and Psychological Measurement, 52, 1003-1019.

Vallerand, R.J., Pelletier, L.G., Blais, M.R., Briere, N.M., Senecal, C., \& Vallieres, E.F. (1993). On the assessment of intrinsic, extrinsic, and amotivation in education: Evidence on the concurrent and construct validity of the Academic Motivation Scale. Educational and Psychological Measurement, 53, 159-172.

Van Dongen-Melman, J.E.W.M., Koot, H.M., \& Verhulst, F.C. (1993). Cross-cultural validation of Harter's SelfPerception Profile for Children in a Dutch sample. Educational and Psychological Measurement, 53, 739-753.
Vlachopoulos, S.P., Karageorghis, C.I., \& Terry, P.C. (2000). Motivation profiles in sport: A self-determination theory perspective. Research Quarterly for Exercise and Sport, 71 (4), 387-397.

Weigand, D.A., \& Broadhurst, C.J. (1998). The relationship among perceived competence, intrinsic motivation, and control perceptions in youth soccer. International Journal of Sport Psychology, 29, 324-338.

Weiss, M.R., \& Ferrer-Caja, E. (2002). Motivational orientations and sport behavior. In Horn, T. (Ed.), Advances in Sport Psychology (pp. 101-183). Champaign, IL: Human Kinetics.

White, R.W. (1959). Motivation reconsidered: The concept of competence. Psychological Review, 66(5), 297-333.

Williams, L. \& Gill, D.L. (1995). The role of perceived competence in the motivation of physical activity. Journal of Sport \& Exercise Psychology, 17, 363-378.

Worth Gavin, D.A., \& Herry, Y. (1996). The French SelfPerception Profile for Children: Score validity and reliability. Educational and Psychological Measurement, 56, 678-700.

\section{Correspondence:}

\section{Eric C.K. TSANG}

Department of Creative Arts and Physical Education (PE Division)

The Hong Kong Institute of Education,

Tai Po, New erritories,

Hong Kong.

Tel: (852) 29487861

E-mail: cktsang@ied.edu.hk 